\title{
Current Status for Gastrointestinal Nematode Diagnosis in Small Ruminants: Where Are We and Where Are We Going?
}

\author{
Sarah Jane Margaret Preston, ${ }^{1}$ Mark Sandeman, ${ }^{2}$ Jorge Gonzalez, ${ }^{3}$ and David Piedrafita ${ }^{4}$ \\ ${ }^{1}$ Biotechnology Research Laboratories, School of Biomedical Sciences, Monash University, Melbourne, VIC 3800, Australia \\ ${ }^{2}$ Faculty of Science, Federation University, Northways Road, Churchill, VIC 3841, Australia \\ ${ }^{3}$ Facultad de Veterinaria, Universidad de Las Palmas de Gran Canaria, Trasmontaña s/n, Arucas, Las Palmas 35413, Spain \\ ${ }^{4}$ School of Applied Sciences \& Engineering, Faculty of Science, Gippsland, Northways Road, Churchill, VIC 3841, Australia
}

Correspondence should be addressed to David Piedrafita; david.piedrafita@federation.edu.au

Received 25 January 2014; Accepted 27 June 2014; Published 2 September 2014

Academic Editor: Mohammed Mahbub Alam

Copyright (C) 2014 Sarah Jane Margaret Preston et al. This is an open access article distributed under the Creative Commons Attribution License, which permits unrestricted use, distribution, and reproduction in any medium, provided the original work is properly cited.

Gastrointestinal nematode (GIN) parasites pose a significant economic burden particularly in small ruminant production systems. Anthelmintic resistance is a serious concern to the effective control of GIN parasites and has fuelled the focus to design and promote sustainable control of practices of parasite control. Many facets of sustainable GIN parasite control programs rely on the ability to diagnose infection both qualitatively and quantitatively. Diagnostics are required to determine anthelmintic efficacies, for targeted treatment programs and selection of animals for parasite resistant breeding. This review describes much of the research investigated to date to improve the current diagnostic for the above practices which is based on counting the number of parasite eggs in faeces.

\section{Introduction}

Small ruminant (goats and sheep) production systems worldwide are significantly constrained by gastrointestinal nematode (GIN) parasites, reducing meat, milk, and fibre production [1-3]. Anthelmintic treatment is the most costeffective current control method in many farm enterprises. However, the ability of parasites to quickly develop resistance to these compounds, particularly if animals are under-dosed or treated under preventative and suppressive treatment regimes, suggests alternative and/or complementary sustainable control programs require adoption [4-8].

Sustainable control programs and guidelines (Table 1) have been introduced to small ruminant producers to prolong the effectiveness of anthelmintics whilst reducing the production loss caused by GIN parasite infections (reviewed by [9-13]). These programs/guidelines involve a combination of chemical and nonchemical strategies to adequately control GIN parasites; however, the success or otherwise of these programs is reliant on an ability to diagnose the parasitic infections qualitatively and quantitatively to estimate the severity of the infection and the potential cost to production traits $[14,15]$.

Alternatives and/or complementary solutions to anthelmintic use are also under investigation with breeding for genetic resistance of the host to infection already in commercial application (http://www.nsip.org; http://www .sheepgenetics.org.au/; http://www.signetfbc.co.uk/). Diagnostic assays that reliably measure the level of genetic resistance are required for such applications and a range of indicators have been or are being investigated and will be reviewed below.

\section{Ideal Characteristics of Diagnostic Markers for GIN Parasite Infections}

The ideal diagnostic test for GIN parasite infections has been described as having the following characteristics $[14,16]$ :

(1) reliability in terms of accuracy and repeatability

(2) ease of measurement 
TABLE 1: Programs/guidelines promoting sustainable GIN parasite control.

\begin{tabular}{lll}
\hline Programs & Country & Resource \\
\hline Wormboss & Australia & http://www.wormboss.com.au/ \\
Wormwise & New Zealand & http://www.beeflambnz.com/farm/tools-resources/wormwise/ \\
Sustainable control of parasites (SCOPS) & United Kingdom & http://www.scops.org.uk/ \\
\hline
\end{tabular}

(3) cost effectiveness

(4) the ability to be used on-farm.

Additional characteristics for diagnostics that could be used in programs aimed at breeding for resistance include

(5) neutral or positive correlations with production traits,

(6) moderate to high heritability.

Although these parameters are easily defined, in practice, there is no universal marker currently that meets these characteristics for GIN parasite diagnosis. The most common test in use currently is the Worm Egg Count (WEC). The WEC test is promoted by government and nongovernment agencies in many commercialised small ruminant industries (Table 1). WEC has many technical disadvantages (Section 2.1) and poor adoption rates by farmers and is, therefore, considered an underutilised diagnostic in many small ruminant production systems [17]. As such, substantial research is being undertaken to find a more usable and accurate measure of infection intensity to assist the development and adoption of sustainable GIN parasite control programs. This review will examine diagnostic markers currently in use and those that are being considered or are currently under development with the potential to replace/improve WEC as a diagnostic marker. These diagnostic markers often involve components of the animals immune system and can be categorised under three major areas: infection-related, immune-related, and inherent markers.

2.1. Infection-Related Diagnostic Markers of GIN Parasitic Infection. Infection-related markers have been characterised by their dependence on current infection and are related to parasite induced pathology such as blood loss or a measure of parasite burden such as number of eggs. Table 2 summarises the markers associated with infection investigated to date.

2.1.1. Worm Egg Counts. WEC involves counting parasitic eggs in freshly collected faeces. Distinctive eggs from GIN parasites such as thin-neck intestinal worm (Nematodirus spp.), tape worm (Moniezia expansa), and whip worm (Trichuris ovis) can be easily identified. However, the worm species that have been identified to cause the largest economic impact on small ruminant production: Trichostrongylus spp., Haemonchus contortus, and Teladorsagia circumcincta are difficult to distinguish by egg morphology and, therefore, require further processing. Identification to at least genus level is important for correct anthelmintic selection but less important for the use of diagnostics as a selection marker in breeding the host for resistance because resistance is usually expressed to a range of parasite species [18-20].
Previously, identification of eggs to species level has involved larval culture requiring at least 7-10 days for egg hatch; however, recently, polymerase chain reaction (PCR) techniques have transformed testing, allowing species identification in less than 24 hours [21-23]. This is an exciting development particularly its potential to identify GIN parasite resistant to anthelmintic classes directly from the faeces as farmers perceive the current protocol to detect anthelmintic resistance involving mini-sheep trials as too difficult and time-consuming [17].

Other research involved in transforming WEC diagnostic into a more time and cost efficient method is to use fluorescently labelled lectins which bind differentially to different GIN parasite species eggs [24-26]. A lectin test for the identification of $H$. contortus eggs is now commercially available through the Australian Government (http://www.sheepcrc.org.au/management/worms-flieslices/rapid-laboratory-test-for-haemonchus-in-worm-eggcounts.php). Both improvements (DNA technology and lectin staining) do not overcome the collection of faeces and both must be performed off-farm by laboratory experts; however, there are reports for the potential of some DNAtechnology platforms to become on-farm diagnostics in the future [27].

Other drawbacks of WEC tests commonly cited in the literature include the low correlation between eggs and worm burden for low fecund worms such as for T. circumcincta and T. colubriformis, inability to detect worms in hypobiosis, and the high variability of eggs between individual subsamples due to aggregation $[15,28]$. In addition, collection of faeces is time and labour intensive and often an unpalatable technique for many farmers and animal health professionals. Despite these disadvantages, WEC tests are promoted commercially as a diagnostic tool to determine if anthelmintics are still effective on farming properties, for targeted anthelmintic treatment strategies and for the selection of animals for breeding parasite resistance through estimated breeding values in many countries [15].

2.1.2. Blood Loss. Measurement of blood loss can indicate the presence of infection with a blood-feeding GIN parasite, such as $H$. contortus, and this parameter has been utilised as a diagnostic tool to target animals for anthelmintic treatment and selection of parasite resistant sheep. Tools available to measure blood loss include packed cell volume (PCV), the Haemonchus dipstick, and FAMACHA ${ }^{\odot}$. PCV is an indicator of anaemia and is usually used in conjunction with WEC to diagnose $H$. contortus infections for research purposes. PCV involves taking blood samples and measuring the percentage of red blood cells. The measurement of blood loss has an 


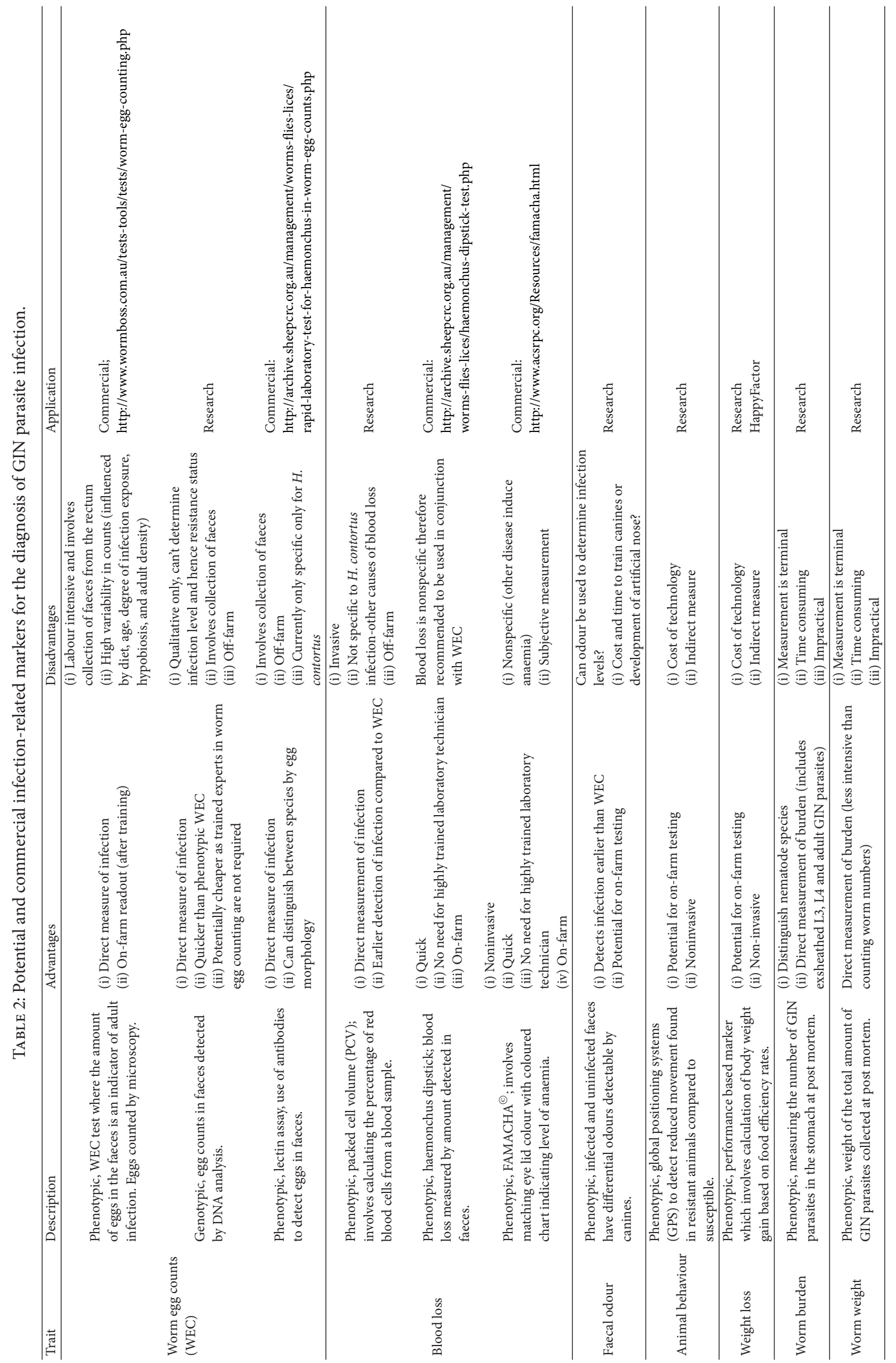


advantage over WEC in that it enables early detection of $H$. contortus infection as blood loss occurs prior to egg production [15]. However, blood sampling is labour intensive for farmers and blood loss can be due to infections other than $H$. contortus such as a severe coccidial or bacterial enteritis infections [14, 29].

To overcome the labour-intensive nature of measuring PCV, the Australian Government commercialised a product, the Haemonchus Dipstick, which measures blood loss by quantifying the amount of blood in the faeces [29]. Although this is a much more practical way of measuring blood loss for producers and can identify infection earlier than WEC to prevent sudden disease outbreaks in high risk periods [11], the concern of the exact origin for the blood loss remains [29]. Therefore, a WEC test is recommended to be used to confirm that blood loss is due to $H$. contortus infection and not another underlying physiological problem or infection [29].

FAMACHA $^{\odot}$ is a $H$. contortus-specific diagnostic tool developed in South Africa, which uses the colour of the eye as an indicator of anaemia due to the parasite's blood feeding activity [30-32]. FAMACHA ${ }^{\odot}$ is a five-point scoring system in which goats or sheep scored at 3-5 are deemed at risk of disease and require treatment [30]. Trials using FAMACHA ${ }^{\odot}$ as a selection tool in targeted selection anthelmintic treatment programs have shown reductions in the number of anthelmintic treatments with minimal production losses [3133]. The major drawback of this tool as with the Haemonchus Dipstick is that anaemia is not exclusively caused by $H$. contortus infections. Despite this, a recent report describes high adoption rates in the southern states of the United States, with 5,000 small ruminant producers being trained through workshops to diagnose anaemic sheep based on FAMACHA ${ }^{\odot}$ and the purchase of 20,000 FAMACHA ${ }^{\odot}$ cards (reviewed by [13]).

FAMACHA $^{\odot}$ can also be applied as a tool to breed $H$. contortus resistant sheep. Trials in United States and South Africa have shown moderate heritability values similar to WEC and PCV and positive associations with increased production traits $[34,35]$. The relative ease and low cost of the FAMACHA $^{\odot}$ system are advantageous for implementation, but it is only effective in areas where livestock are dominantly infected by $H$. contortus, and, as outlined above for the Haemonchus Dipstick, it lacks specificity.

2.1.3. Faecal Odour. Only one research group has investigated the use of odour to detect GIN parasite infections, by training canines to detect the scent [36]. The limited research in odour detection of GIN parasites is surprising, given anecdotal evidence of producers being able to smell GIN parasite infections, in combination with the routine use of canines to detect explosives, illegal drugs, and human remains and detection of humans with ill-health (reviewed by [37, 38]). The work indicated that this method for detecting GIN parasite infection has high sensitivity, detecting T. circumcincta infections in sheep as early as seven days post oral infection with an $85 \%$ accuracy [36], potentially meaning that the odour diagnosis of GIN parasite infections could occur before egg laying and before clinical symptoms appear.
Richards et al. [36] suggested that further work should focus on defining the chemical composition of the detectable odour to transform this knowledge into a detection device. The potential of this device to operate on-farm is promising, however, whether level of odour correlates strongly with infection level, a prerequisite for likely commercial success, requires investigation.

2.1.4. Animal Behaviour. Parasite infections influence animal behaviour and some studies have been conducted to determine whether changes in behaviour would allow identification of parasite resistant or susceptible animals [39-41]. A recent study using a global positioning system (GPS) tracking device to monitor the behaviour of sheep under natural field infection conditions found that animals with higher WEC (more susceptible) travelled significantly greater distances than animals with lower WEC [42]. Theories as to why animals with heavier infections travelled greater distances included that these animals need to graze for longer periods to cope with protein loss due to infection and visit water sources more frequently due to an increased thirst [42]. GPS devices are still too expensive to be considered as a commercial tool for diagnosing GIN parasite resistant sheep, but they are an excellent research tool and further studies would be of interest.

2.1.5. Weight Loss. The Happy Factor is a performance based marker which involves calculation of body weight gain based on food efficiency rates [43]. Animals which do not reach the predicted target are treated with anthelmintics. An advantage of using body weight scores is that condition loss is an early symptom of infection and is an economically important trait [43]. A recent study based in a commercial setting in the United Kingdom showed that this approach resulted in a $50 \%$ decrease in anthelmintic treatment [44]. However, animals needed to be weighed fortnightly, which the authors acknowledge may not be practical in all livestock production settings.

2.1.6. Worm Number and Weight. Worm number and weight is the most direct measurement of determining GIN parasite infection levels and is consequently considered the gold standard for estimating parasitic worm burden [14]. Worm number involves counting the parasites in the gastrointestinal tract; a proportion of the worm population is usually measured as an estimate of the total [45]. Infective larval stages (L3, L4) and adult female and male GIN parasites can be enumerated and differentiated by morphology providing important information on the target of host resistance and are required for testing the activity of new anthelmintics [14]. Measuring worm weight involves collecting the parasites and recording their bulk weight. However, these markers can obviously only be taken at necropsy, are labour intensive, and are consequently only useful for research purposes.

2.2. Immune-Related Diagnostic Markers of GIN Parasitic Infection. It has long been established that the immune system plays a major role in resistance to GIN parasite infection 
[46, 47]. Immune cell depletion and cytokine profile studies have shown that resistance to infection is dependent on the induction of the type two (T2) or the "allergic" phenotype response [48-50]. The Th2 immune response is characterised by the differentiation of $\mathrm{T}$ cells that produce the cytokines IL-4, IL-5, IL-9, and IL-13, the proliferation and recruitment of effector cells, and eosinophils, mucosal mast cells and globular leukocytes, along with increased mucus secretion and generation of parasite-specific antibodies such as $\operatorname{IgA}$, $\operatorname{Ig} G_{1}$ and $\operatorname{IgE}[48,51]$.

However, it is now recognised that manifestations before and after the T2 "allergic" immune response are also vitally important for successful control of infection [52]. Detailed studies in mice have shown the importance of correct innate receptor expression and functioning to recognise pathogenassociated molecular patterns and damage-associated molecular patterns (reviewed by [53]). Furthermore, the downregulation of the immune response through the recruitment of T regulatory cells is important in dictating disease outcomes. Innate receptors such as the toll-like receptors and alarmins have recently been identified in sheep [54, 55] and the suppression of the $\mathrm{T}$ regulatory pathways has been described as a mechanism for susceptibility in Scottish Black face sheep infected with T. circumcincta [56].

Thus, given the involvement of the abovementioned cells and mediators identified in development of immunity to GIN parasites, many of these immune parameters have been investigated as selection tools for identification of GIN parasite resistant sheep. However, due to the diverse and complex nature of the immune response, few of these parameters have as yet been substantiated as GIN parasite resistant markers [57, 58]. Table 3 outlines the immunerelated selection parameters investigated to date.

2.2.1. Antibodies. Local and peripheral antibody production is associated with GIN parasiteinfection with high levels of parasite-specific IgG $\mathrm{I}_{1}$, IgE, and IgA correlating with low parasite burden $[50,59]$. The role of each antibody isotype in resistance is not fully understood but IgA has been consistently correlated with reduced worm length and fecundity in sheep infected with $T$. circumcincta [60-62]. In H. contortus infections, serum IgA and $\operatorname{IgG}_{1}$ were consistently higher in genetically resistant sheep compared to randomly bred animals indicating the potential for selection of resistance based on high parasite specific antibody titre [50]. However, the procedures for measuring antibodies in the periphery, while accessible, often give an inaccurate representation of antibody levels (e.g., mucosal) at the infection site [6366]. Additionally, there is little evidence to support a role for serum antibodies in resistance as opposed to localised antibody production at the site of infection which is more likely to influence the resistance status of an animal [67].

To overcome these issues, other sources of antibodies besides blood have been examined. In faeces, $\mathrm{IgG}_{1}$ and $\operatorname{IgA}$ can be detected in resistant-bred animals based on low WEC for $H$. contortus [50]. However, false positive readouts due to nonspecific antigen-protein binding terminated development of an assay [68]. The revelation that protective antibodies against larvae potentially derived from the gut associated lymphoid tissue in the intestinal mucosa could be easily detected in the saliva has resulted in the commercialisation of a diagnostic test, the CarLA Saliva Test, for selection of GIN parasite resistant animals [58, 66, 69]. Detection of salivary antibodies is advantageous in comparison to WEC due to earlier detection (at the L3 stage rather than the adult) and saliva from sheep is more appealing for producers to collect than faeces. However to develop an antibody response animals require prior and repeated exposure (not suitable in young animals less than six months which are at most risk) and a certain infection threshold for optimal detection [58], and these limitations may make it impractical for widespread industry adoption.

2.2.2. Eosinophilia. Peripheral blood eosinophilia is associated with GIN parasite infections and has been consistently reported to be higher in sheep resistant to $H$. contortus, T. circumcincta, and T. colubriformis [70-73]. Such findings led to the evaluation of peripheral blood eosinophilia as a potential marker of GIN parasite resistance. Results correlating blood eosinophilia during $H$. contortus infections with low WEC have been inconsistent (reviewed by [28]), but promising correlations have been found in other GIN parasite infections including T. colubriformis and T. circumcincta [74]. An early study showed that sheep which responded strongly to vaccination with irradiated T. colubriformis had higher blood eosinophilia than low-vaccine responder sheep [71]. This was supported by an extension study which showed that, following vaccination and challenge with the mitogen phytohaemagglutinin, blood eosinophilia was highly correlated to resistance to T. colubriformis in random-bred sheep [72]. However, the estimated heritability of blood eosinophilia for selection of resistant sheep was found to be only $43 \%$ as effective as using WEC as a selection parameter [75]. Animal behavioural studies have identified that resistant sheep which had increased locomotive patterns also had higher basal circulatory eosinophilia concluding that parasite resistant sheep were also resistant to stress [41]. These results supported those of earlier research in which it was noted that animal handling in cattle generated increased blood basal levels of eosinophils [76]. A more recent study in Scottish Black-faced sheep infected with $T$. circumcincta also found a strong correlation between eosinophilia and resistance and found that the relationship had similar heritability as WEC [60]. However, this relationship with eosinophilia and resistance was age-dependent, existing only in lambs aged 37 months [60]. In general, like serum antibodies, the value of peripheral eosinophils as a marker of GIN parasite resistance is confounded by the dynamic nature of the immune system and the changing relationship between the host and parasite interaction [77].

2.2.3. Ghrelin. Ghrelin is a satiety-regulating hormone, stimulating appetite and the release of growth hormones [78]. In sheep, reduced appetite is a symptom of GIN parasitic infection. Recent work has shown that $H$. contortus and $T$. colubriformis resistant and susceptible lines of Merino sheep 


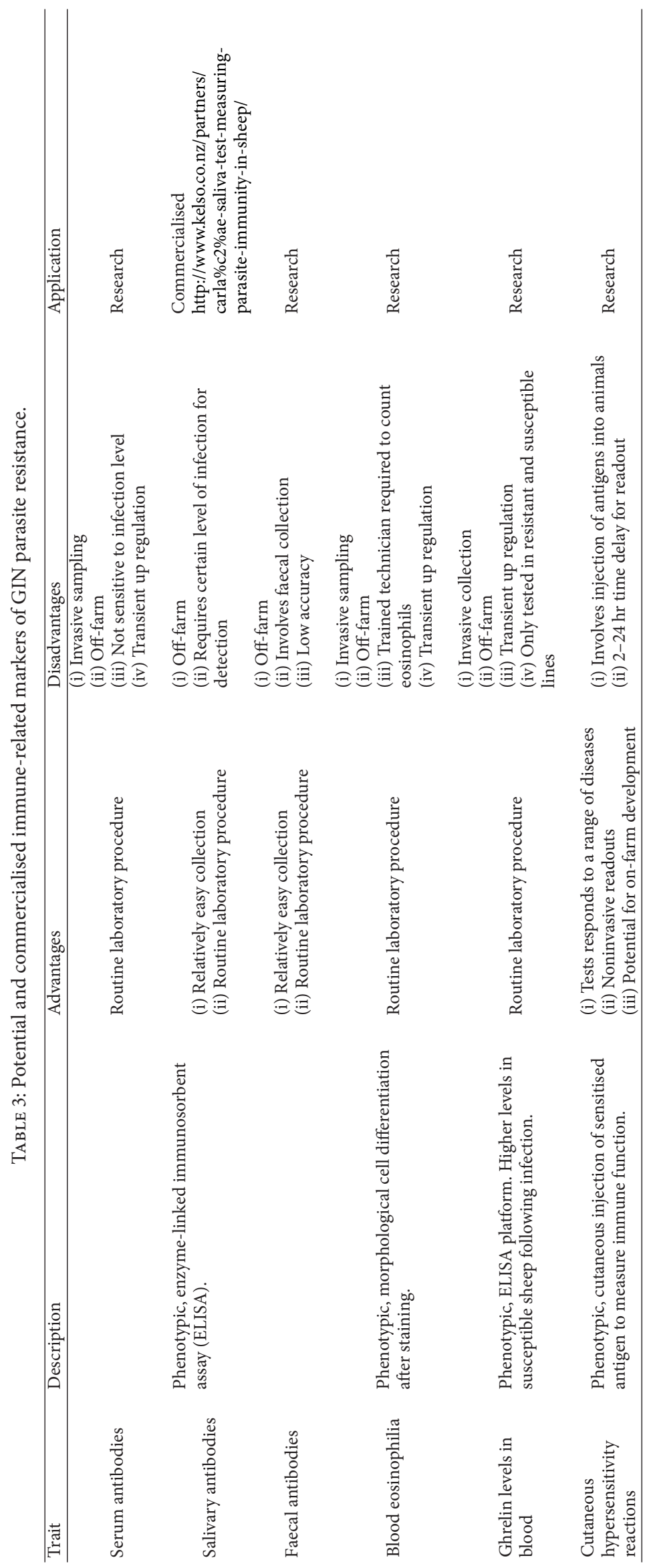


are divergent in their ghrelin expression [79]. Resistant sheep were observed to have lower basal levels, but following GIN parasite challenge the resistant sheep had higher ghrelin expression (gene and protein) early postinfection than susceptible animals [79]. The function of ghrelin in resistance to GIN parasites is still under investigation but it is believed that the interaction could be direct as ghrelin has previously been shown to have anti-inflammatory properties $[80,81]$ and immune cells circulating in the blood were found to express ghrelin receptors [79]. A competitive ELISA to detect circulating ghrelin levels has been developed [79] but heritability and the association with increased animal productivity will need to be investigated to order to determine its effectiveness as a marker of GIN parasite resistance.

2.3. Diagnostic Based on Inherent Markers. Inherent markers of GIN parasite resistance are categorised as innate markers independent of infection and age of the animal. Consequently, markers based on inherent traits are only useful for breeding of parasite/disease resistant animals. Inherent markers which have been investigated are discussed below.

2.3.1. Blood Type. Early work suggested a link between sheep blood type and resistance to GIN parasites [82]. In sheep, haemoglobin is controlled by two major alleles A and B [9]. Studies have shown that sheep with blood type HbAA are more resistant to $H$. contortus and $T$. circumcincta infections than blood types $\mathrm{HbAB}$ and $\mathrm{HbBB}$ [82-84]. A similar study investigated blood type as a factor contributing to the responder/nonresponder phenomenon in vaccinated sheep against T. colubriformis [85]. Results showed that blood type could not be used to predict if a sheep would respond to vaccination as no associations were found between blood type and WEC during either primary or secondary infections [85]. Further research in this area has not supported the relationship between blood type and resistance to GIN parasites [9].

\subsubsection{Immune Cell Markers and Cytokines: Major Histo-} compatibility Complex and Interferon Gamma. The major histocompatibility complex (MHC) and interferon gamma $(\mathrm{IFN}-\gamma)$ genes have had the most attention as candidate genetic markers of GIN parasite resistance. Investigations of polymorphisms within the genes that control MHC class I and II expression stemmed from mice and guinea pig studies in which associations between MHC class II polymorphisms and susceptibility to Trichinella spiralis and T. colubriformis were identified [86, 87]. Ovine MHC differs from humans and mice in that the MHC class II is only encoded by two genes, HLA-DQ and HLA-DR [88]. Most attention has been focused on finding associations between $H L A-D R$ isoforms and resistance as it is more polymorphic than $H L A-D Q$ and is highly expressed on antigen-presenting cells [87]. The translation from rodent models to sheep produced inconsistent results with some researchers finding significant associations between gene variants of $\mathrm{MHC}$ and parasite resistance [8993], whereas other researchers did not [87, 94].

A recent study combining quantitative trait loci (QTL) from cattle, mice, rats, humans, and sheep associated with resistance to internal parasite identified 14 common pathways, four directly involving MHC class II expression [95]. This study also reported the INF- $\gamma$ pathway to be associated with parasite susceptibility supporting earlier genomic work [96-98].

Identifying single gene markers associated with resistance to GIN parasites is difficult as resistance to parasites is considered to be polygenic with hundreds to thousands mutations responsible for the resistant phenotype $[99,100]$. However, research continues in the area of genetic markers as they have the advantage over phenotypic markers of measurement prior to birth [87], meaning that producers can make productivity decisions early. Traditionally, application of genetic tools to the selection of animals has been hampered by costs. However, genetic testing for the selection of enhanced animal production traits has now become relatively inexpensive with the development of the ovine single nucleotide polymorphism (SNP) CHIP (OvineSNP50 genotyping BeadChip, Illumina). While the expense of genomic technology has reduced, substantial and continuous investment is essential as large reference and validation animal flocks which closely represent the within and across breed diversity for given traits are required to increase the accuracy of genomic predictions before new genetic traits can enter the industry [101].

2.3.3. Markers of Immunocompetence/Disease Resistant Animals. Breeding for resistance to one infection may result in susceptibility to other pathogens. This statement is based on the theory that natural selection has stabilised intermediate levels of antibody and cell mediated responses to enable an organism to survive against a range of diseases [102]. Consequently, work is now being focused on finding immune traits that give an indication of the overall responsiveness of the immune system. This has been termed immunocompetence.

Recent work in the pork industry has focused on the identification of immunocompetence using traits that are easily measured and heritable $[103,104]$ and has identified a range of measurable immune traits that are strongly heritable by measuring the type and level of immune cells in blood samples as well as the immune cell's ability to respond to in vitro stimulation. Whether these traits can predict disease resistance is still under development.

Cutaneous hypersensitivity reactions are routinely used in humans to determine allergic responses and involve injection of antigens to stimulate a localised inflammatory response. An extension of these studies is whether these inflammatory responses to certain antigens predict the susceptibility or resistant status of animals. In the Canadian dairy industry, researchers have measured delayed hypersensitivity reactions after cutaneous antigen injections to create individual estimated breeding values of cell mediated immunity [105]. These values and estimated breeding values for antibody responses have been correlated to the prevalence of diseases such as mastitis [106]. Additionally, several immune traits measured in the serum have been associated with dairy cattle health in Scotland with higher ratios of CD4+ : CD8+ $\mathrm{T}$ lymphocytes associated with reduced occurrences of subclinical mastitis during the lactation period [107]. 
Cutaneous hypersensitivity reactions have also been investigated in the small livestock industry. An early study examined cutaneous hypersensitivity reactions as a diagnostic for the bacterial infection, Chlamydia psittaci, with sheep giving a positive wheal reaction (an increase in eyelid skin thickness), correlating with a decrease in spontaneous lamb abortions [108]. Cutaneous hypersensitivity reactions have been assessed as a potential tool for the identification of sheep resistance to $T$. colubriformis and $H$. contortus infection [72, 109, 110]. Rothwell et al. [72] investigated immune responsiveness in T. colubriformis-resistant and susceptible lines of sheep, measuring blood eosinophilia following an intradermal injection of exsheathed L3 (exsheathed L3) and suggest that cutaneous hypersensitivity reactions may be a reliable way to measure the immune system's ability to respond effectively to disease and potentially distinguish between disease resistant and susceptible animals.

Cutaneous hypersensitivity reactions may be a valuable research tool for identifying differential immune responses to various stimuli, due to the relative ease of data collection and sample site monitoring. As research has now implicated an array of immune pathways responsible for resistance to GIN parasites [97, 98], cutaneous hypersensitivity reactions have the potential to explore these mechanisms in more detail in a nonterminal manner and with further development, potential on-farm application. However, limited research to date has focused on cutaneous hypersensitivity reactions to discern parasite resistant animals and the potential of this approach remains unknown. The cost-benefit ratio for producers will also need to be explored and may only be suitable for certain animal production industries.

\section{Conclusion}

Currently there are two primary reasons for use of a diagnostic marker to detect GIN parasites in small ruminants:

(1) conserving the effectiveness of anthelmintics,

(2) breeding animals with resistance to infection.

Advances in this field have provided a number of diagnostics that are excellent for laboratory-based research with recent molecular advances improving the accuracy and costeffectiveness of larval identification. However, advances in practical on-farm diagnostics suitable to replace WEC have been limited with many commercialised products being recommended to complement rather than replace WEC. However, a number of immune-based diagnostics show some promise and further understanding of the parasite epidemiology; infection and immune responses of the host will hopefully provide further advancements in the area of practical diagnostics for parasite control in small ruminants.

\section{Conflict of Interests}

The authors declare that there is no conflict of interests regarding the publication of this paper.

\section{References}

[1] J. E. Miller and D. W. Horohov, "Immunological aspects of nematode parasite control in sheep," Journal of Animal Science, vol. 84, pp. E124-E132, 2006.

[2] M. B. Molento, "Parasite control in the age of drug resistance and changing agricultural practices," Veterinary Parasitology, vol. 163, no. 3, pp. 229-234, 2009.

[3] D. Piedrafita, H. W. Raadsma, J. Gonzalez, and E. Meeusen, "Increased production through parasite control: can ancient breeds of sheep teach us new lessons?" Trends in Parasitology, vol. 26, no. 12, pp. 568-573, 2010.

[4] P. J. Waller, K. M. Dash, I. A. Barger, L. F. le Jambre, and J. Plant, "Anthelmintic resistance in nematode parasites of sheep: learning from the Australian experience," Veterinary Record, vol. 136, no. 16, pp. 411-413, 1995.

[5] J. A. van Wyk, "Refugia-overlooked as perhaps the most potent factor concerning the development of anthelmintic resistance," Onderstepoort Journal of Veterinary Research, vol. 68, no. 1, pp. 55-67, 2001.

[6] R. B. Besier and S. C. J. Love, "Anthelmintic resistance in sheep nematodes in Australia: the need for new approaches," Australian Journal of Experimental Agriculture, vol. 43, no. 12, pp. 1383-1391, 2003.

[7] R. G. Woodgate and R. B. Besier, "Sustainable use of anthelmintics in an Integrated Parasite Management Program for sheep nematodes," Animal Production Science, vol. 50, no. 6, pp. 440-443, 2010.

[8] F. Jackson, D. Bartley, Y. Bartley, and F. Kenyon, "Worm control in sheep in the future," Small Ruminant Research, vol. 86, no. $1-3$, pp. 40-45, 2009.

[9] G. D. Gray, "The use of genetically resistant sheep to control nematode parasitism," Veterinary Parasitology, vol. 72, no. 3-4, pp. 345-366, 1997.

[10] P. J. Waller, "International approaches to the concept of integrated control of nematode parasites of livestock," International Journal for Parasitology, vol. 29, no. 1, pp. 155-164, 1999.

[11] L. P. Kahn and R. G. Woodgate, "Integrated parasite management: products for adoption by the Australian sheep industry," Veterinary Parasitology, vol. 186, no. 1-2, pp. 58-64, 2012.

[12] G. D. Gray, J. G. Connell, and V. Phimphachanhvongsod, "Worms in smallholder livestock systems: technologies and practices that make a difference," Veterinary Parasitology, vol. 186, no. 1-2, pp. 124-131, 2012.

[13] T. H. Terrill, J. E. Miller, J. M. Burke, J. A. Mosjidis, and R. M. Kaplan, "Experiences with integrated concepts for the control of Haemonchus contortus in sheep and goats in the United States," Veterinary Parasitology, vol. 186, no. 1-2, pp. 28-37, 2012.

[14] I. G. Colditz, "Challenges to the development of new tests for diagnosis of infection and prediction of resistance of sheep to gastrointestinal nematodes," Tropical Biomedicine, vol. 25, no. 1, pp. 41-49, 2008.

[15] P. W. Hunt and J. Lello, "How to make DNA count: DNAbased diagnostic tools in veterinary parasitology," Veterinary Parasitology, vol. 186, no. 1-2, pp. 101-108, 2012.

[16] R. G. Windon, "Genetic control of resistance to helminths in sheep," Veterinary Immunology and Immunopathology, vol. 54, no. 1-4, pp. 245-254, 1996.

[17] R. G. Woodgate and S. Love, "WormKill to WormBoss-Can we sell sustainable sheep worm control?" Veterinary Parasitology, vol. 186, no. 1-2, pp. 51-57, 2012. 
[18] D. B. Adams, B. H. Anderson, and R. G. Windon, "Crossimmunity between Haemonchus contortus and Trichostrongylus colubriformis in sheep," International Journal for Parasitology, vol. 19, no. 7, pp. 717-722, 1989.

[19] L. Gruner, J. Bouix, and J. C. Brunel, "High genetic correlation between resistance to Haemonchus contortus and to Trichostrongylus colubriformis in INRA 401 sheep," Veterinary Parasitology, vol. 119, no. 1, pp. 51-58, 2004.

[20] K. E. Kemper, D. G. Palmer, S. M. Liu, J. C. Greeff, S. C. Bishop, and L. J. E. Karlsson, "Reduction of faecal worm egg count, worm numbers and worm fecundity in sheep selected for worm resistance following artificial infection with Teladorsagia circumcincta and Trichostrongylus colubriformis," Veterinary Parasitology, vol. 171, no. 3-4, pp. 238-246, 2010.

[21] F. Roeber, J. W. A. Larsen, N. Anderson et al., "A molecular diagnostic tool to replace larval culture in conventional faecal egg count reduction testing in sheep," PLoS ONE, vol. 7, no. 5, Article ID e37327, 2012.

[22] J. P. A. Sweeny, U. M. Ryan, I. D. Robertson, D. Niemeyer, and P. W. Hunt, "Development of a modified molecular diagnostic procedure for the identification and quantification of naturally occurring strongylid larvae on pastures," Veterinary Parasitology, vol. 190, no. 3-4, pp. 467-481, 2012.

[23] F. Roeber, A. R. Jex, and R. B. Gasser, "Advances in the diagnosis of key gastrointestinal nematode infections of livestock, with an emphasis on small ruminants," Biotechnology Advances, vol. 31, pp. 1135-1152, 2013.

[24] I. G. Colditz, L. F. Le Jambre, and R. Hosse, "Use of lectin binding characteristics to identify gastrointestinal parasite eggs in faeces," Veterinary Parasitology, vol. 105, no. 3, pp. 219-227, 2002.

[25] K. Hillrichs, T. Schnieder, A. B. Forbes, D. C. Simcock, K. C. Pedley, and H. V. Simpson, "Use of fluorescent lectin binding to distinguish Teladorsagia circumcincta and Haemonchus contortus eggs, third-stage larvae and adult worms," Parasitology Research, vol. 110, no. 1, pp. 449-458, 2012.

[26] D. G. Palmer and I. L. McCombe, "Lectin staining of trichostrongylid nematode eggs of sheep: rapid identification of Haemonchus contortus eggs with peanut agglutinin," International Journal for Parasitology, vol. 26, no. 4, pp. 447-450, 1996.

[27] R. B. Gasser, N. J. Bott, N. B. Chilton, P. Hunt, and I. Beveridge, "Toward practical, DNA-based diagnostic methods for parasitic nematodes of livestock-bionomic and biotechnological implications," Biotechnology Advances, vol. 26, no. 4, pp. 325-334, 2008.

[28] R. R. Woolaston and R. L. Baker, "Prospects of breeding small ruminants for resistance to internal parasites," International Journal for Parasitology, vol. 26, no. 8-9, pp. 845-855, 1996.

[29] I. G. Colditz and L. F. Le Jambre, "Development of a faecal occult blood test to determine the severity of Haemonchus contortus infections in sheep," Veterinary Parasitology, vol. 153, no. 1-2, pp. 93-99, 2008.

[30] J. A. van Wyk and G. F. Bath, "The FAMACHA system for managing haemonchosis in sheep and goats by clinically identifying individual animals for treatment," Veterinary Research, vol. 33, pp. 509-529, 2002.

[31] R. M. Kaplan, J. M. Burke, T. H. Terrill et al., "Validation of the FAMACHA eye color chart for detecting clinical anemia in sheep and goats on farms in the Southern United States," Veterinary Parasitology, vol. 123, no. 1-2, pp. 105-120, 2004.

[32] A. F. Vatta, B. A. Letty, M. J. van der Linde, E. F. van Wijk, J. W. Hansen, and R. C. Krecek, "Testing for clinical anaemia caused by Haemonchus spp. in goats farmed under resourcepoor conditions in South Africa using an eye colour chart developed for sheep," Veterinary Parasitology, vol. 99, no. 1, pp. $1-14,2001$.

[33] F. Kenyon and F. Jackson, "Targeted flock/herd and individual ruminant treatment approaches," Veterinary Parasitology, vol. 186, no. 1-2, pp. 10-17, 2012.

[34] J. M. Burke and J. E. Miller, "Use of FAMACHA system to evaluate gastrointestinal nematode resistance/resilience in offspring of stud rams," Veterinary Parasitology, vol. 153, no. 1-2, pp. 85-92, 2008.

[35] D. G. Riley and J. A. van Wyk, "Genetic parameters for FAMACHA score and related traits for host resistance/resilience and production at differing severities of worm challenge in a Merino flock in South Africa," Veterinary Parasitology, vol. 164, no. 1, pp. 44-52, 2009.

[36] K. M. Richards, S. J. Cotton, and R. Sandeman, "The use of detector dogs in the diagnosis of nematode infections in sheep feces," Journal of Veterinary Behavior: Clinical Applications and Research, vol. 3, no. 1, pp. 25-31, 2008.

[37] D. L. Wells, "Dogs as a diagnostic tool for ill health in humans," Alternative Therapies in Health and Medicine, vol. 18, no. 2, pp. $12-17,2012$

[38] N. Lorenzo, T. Wan, R. J. Harper et al., "Laboratory and field experiments used to identify Canis lupus var. familiaris active odor signature chemicals from drugs, explosives, and humans," Analytical and Bioanalytical Chemistry, vol. 376, no. 8, pp. 12121224, 2003.

[39] D. B. Adams and L. R. Fell, "The effect of infection with the abomasal nematode, Haemonchus contortus, on the avoidance behaviour of sheep in a motivational-choice test," International Journal for Parasitology, vol. 27, no. 6, pp. 665-673, 1997.

[40] L. R. Fell, J. J. Lynch, D. B. Adams, G. N. Hinch, R. K. Munro, and H. I. Davies, "Behavioural and physiological effects in sheep of a chronic stressor and a parasite challenge," Australian Journal of Agricultural Research, vol. 42, no. 8, pp. 1335-1346, 1991.

[41] M. A. Hohenhaus, M. J. Josey, C. Dobson, and P. M. Outteridge, "The eosinophil leucocyte, a phenotypic marker of resistance to nematode parasites, is associated with calm behaviour in sheep," Immunology and Cell Biology, vol. 76, no. 2, pp. 153-158, 1998.

[42] G. Falzon, D. Schneider, M. Trotter, and D. W. Lamb, "A relationship between faecal egg counts and the distance travelled by sheep," Small Ruminant Research, vol. 111, no. 1-3, pp. 171-174, 2013.

[43] A. W. Greer, F. Kenyon, D. J. Bartley et al., "Development and field evaluation of a decision support model for anthelmintic treatments as part of a targeted selective treatment (TST) regime in lambs," Veterinary Parasitology, vol. 164, no. 1, pp. 12-20, 2009.

[44] V. Busin, F. Kenyon, N. Laing et al., "Addressing sustainable sheep farming: application of a targeted selective treatment approach for anthelmintic use on a commercial farm," Small Ruminant Research, vol. 110, no. 2-3, pp. 100-103, 2013.

[45] M. J. Stear and S. C. Bishop, “The curvilinear relationship between worm length and fecundity of Teladorsagia circumcincta," International Journal for Parasitology, vol. 29, no. 5, pp. 777-780, 1999.

[46] B. L. Presson, G. D. Gray, and S. K. Burgess, "The effect of immunosuppression with dexamethasone on Haemonchus contortus infections in genetically resistant Merino sheep," Parasite Immunology, vol. 10, no. 6, pp. 675-680, 1988. 
[47] M. T. Peña, J. E. Miller, and D. W. Horohov, "Effect of dexamethasone treatment on the immune response of Gulf Coast Native lambs to Haemonchus contortus infection," Veterinary Parasitology, vol. 119, no. 2-3, pp. 223-235, 2004.

[48] A. Balic, V. M. Bowles, and E. N. T. Meeusen, "Cellular profiles in the abomasal mucosa and lymph node during primary infection with Haemonchus contortus in sheep," Veterinary Immunology and Immunopathology, vol. 75, no. 1-2, pp. 109-120, 2000.

[49] E. N. T. Meeusen, A. Balic, and V. Bowles, "Cells, cytokines and other molecules associated with rejection of gastrointestinal nematode parasites," Veterinary Immunology and Immunopathology, vol. 108, no. 1-2, pp. 121-125, 2005.

[50] H. S. Gill, D. L. Watson, and M. R. Brandon, "Monoclonal antibody to $\mathrm{CD}^{+} \mathrm{T}$ cells abrogates genetic resistance to Haemonchus contortus in sheep," Immunology, vol. 78, no. 1, pp. 43-49, 1993.

[51] A. Pernthaner, S. Cole, L. Morrison, R. Green, R. J. Shaw, and W. R. Hein, "Cytokine and antibody subclass responses in the intestinal lymph of sheep during repeated experimental infections with the nematode parasite Trichostrongylus colubriformis," Veterinary Immunology and Immunopathology, vol. 114, no. 1-2, pp. 135-148, 2006.

[52] R. M. Maizels, J. P. Hewitson, and K. A. Smith, "Susceptibility and immunity to helminth parasites," Current Opinion in Immunology, vol. 24, no. 4, pp. 459-466, 2012.

[53] B. Verstak, P. Hertzog, and A. Mansell, "Toll-like receptor signalling and the clinical benefits that lie within," Inflammation Research, vol. 56, no. 1, pp. 1-10, 2007.

[54] M. Menzies and A. Ingham, "Identification and expression of Toll-like receptors 1-10 in selected bovine and ovine tissues," Veterinary Immunology and Immunopathology, vol. 109, no. 1-2, pp. 23-30, 2006.

[55] N. M. Andronicos, J. McNally, A. C. Kotze, P. W. Hunt, and A. Ingham, "Trichostrongylus colubriformis larvae induce necrosis and release of IL33 from intestinal epithelial cells in vitro: implications for gastrointestinal nematode vaccine design," International Journal for Parasitology, vol. 42, no. 3, pp. 295-304, 2012.

[56] A. G. Gossner, V. M. Venturina, D. J. Shaw, J. M. Pemberton, and J. Hopkins, "Relationship between susceptibility of Blackface sheep to Teladorsagia circumcincta infection and an inflammatory mucosal T cell response," Veterinary Research, vol. 43, no. 1, article 26, 2012.

[57] A. R. Williams, "Immune-mediated pathology of nematode infection in sheep-is immunity beneficial to the animal?" Parasitology, vol. 138, no. 5, pp. 547-556, 2011.

[58] R. J. Shaw, C. A. Morris, and M. Wheeler, "Genetic and phenotypic relationships between carbohydrate larval antigen (CarLA) IgA, parasite resistance and productivity in serial samples taken from lambs after weaning," International Journal for Parasitology, vol. 43, no. 8, pp. 661-667, 2013.

[59] A. R. Williams, D. G. Palmer, I. H. Williams, P. E. Vercoe, D. L. Emery, and L. J. E. Karlsson, "Relationships between immune indicators of parasitic gastroenteritis, nematode burdens and faecal dry matter in sheep," Animal Production Science, vol. 50, no. 3, pp. 219-227, 2010.

[60] M. J. Stear, N. G. Henderson, A. Kerr et al., "Eosinophilia as a marker of resistance to Teladorsagia circumcincta in Scottish Blackface lambs," Parasitology, vol. 124, no. 5, pp. 553-560, 2002.

[61] N. G. Henderson and M. J. Stear, "Eosinophil and IgA responses in sheep infected with Teladorsagia circumcincta," Veterinary
Immunology and Immunopathology, vol. 112, no. 1-2, pp. 62-66, 2006.

[62] M. Benothman, M. Stear, S. Mitchel, O. Abuargob, R. Vijayan, and S. Kumar, "Measurement of IgA activity against parasitic larvae, fecal egg count and growth rate in naturally infected sheep," Current Trends in Biotechnology and Pharmacy, vol. 4, no. 2, pp. 665-672, 2010.

[63] J. Mestecky, J. R. McGhee, S. M. Michalek, R. R. Arnold, S. S. Crago, and J. L. Babb, "Concept of the local and common mucosal immune response," Advances in Experimental Medicine and Biology, vol. 107, pp. 185-192, 1978.

[64] V. M. Bowles, M. R. Brandon, and E. Meeusen, "Characterization of local antibody responses to the gastrointestinal parasite Haemonchus contortus," Immunology, vol. 84, no. 4, pp. 669674, 1995.

[65] N. Robinson, J. Pleasance, D. Piedrafita, and E. N. Meeusen, "The kinetics of local cytokine and galectin expression after challenge infection with the gastrointestinal nematode, Haemonchus contortus," International Journal for Parasitology, vol. 41, no. 5, pp. 487-493, 2011.

[66] R. J. Shaw, C. A. Morris, M. Wheeler, M. Tate, and I. A. Sutherland, "Salivary IgA: a suitable measure of immunity to gastrointestinal nematodes in sheep," Veterinary Parasitology, vol. 186, no. 1-2, pp. 109-117, 2012.

[67] D. R. Maass, G. B. L. Harrison, W. N. Grant, and C. B. Shoemaker, "Three surface antigens dominate the mucosal antibody response to gastrointestinal L3-stage strongylid nematodes in field immune sheep," International Journal for Parasitology, vol. 37, no. 8-9, pp. 953-962, 2007.

[68] T. M. Ellis, A. Gregory, R. Turnor, M. Kalkhoven, and R. H. Wroth, "Detection of Haemonchus contortus surface antigen in faeces from infected sheep," Veterinary Parasitology, vol. 51, no. 1-2, pp. 85-97, 1993.

[69] G. B. L. Harrison, H. D. Pulford, E. E. Doolin, A. Pernthaner, C. B. Shoemaker, and W. R. Hein, "Antibodies to surface epitopes of the carbohydrate larval antigen CarLA are associated with passive protection in strongylid nematode challenge infections," Parasite Immunology, vol. 30, no. 11-12, pp. 577-584, 2008.

[70] A. E. Kimambo, J. C. MacRae, and P. J. S. Dewey, “The effect of daily challenge with Trichostrongylus colubriformis larvae on the nutrition and performance of immunologically-resistant sheep," Veterinary Parasitology, vol. 28, no. 3, pp. 205-212, 1988.

[71] H. J. S. Dawkins, R. G. Windon, and G. K. Eagleson, "Eosinophil responses in sheep selected for high and low responsiveness to Trichostrongylus colubriformis," International Journal for Parasitology, vol. 19, no. 2, pp. 199-205, 1989.

[72] T. L. W. Rothwell, R. G. Windon, B. A. Horsburgh, and B. H. Anderson, "Relationship between eosinophilia and responsiveness to infection with Trichostrongylus colubriformis in sheep," International Journal for Parasitology, vol. 23, no. 2, pp. 203-211, 1993.

[73] G. Terefe, C. Lacroux, F. Prévot et al., "Eosinophils in Haemonchus contortus-infected resistant and susceptible breeds of sheep: abomasal tissue recruitment and in vitro functional state," Veterinary Parasitology, vol. 165, no. 1-2, pp. 161-164, 2009.

[74] P. G. C. Douch, R. S. Green, C. A. Morris, J. C. Mcewan, and R. G. Windon, "Phenotypic markers for selection of nematoderesistant sheep," International Journal for Parasitology, vol. 26, no. 8-9, pp. 899-911, 1996.

[75] R. R. Woolaston, P. Manueli, S. J. Eady et al., "The value of circulating eosinophil count as a selection criterion for resistance 
of sheep to trichostrongyle parasites," International Journal for Parasitology, vol. 26, no. 1, pp. 123-126, 1996.

[76] R. J. Gartner, L. L. Callow, C. K. Granzien, and P. M. Pepper, "Variations in the concentration of blood constituents in relation to the handling of cattle," Research in Veterinary Science, vol. 10, no. 1, pp. 7-12, 1969.

[77] S. C. Bishop, "Possibilities to breed for resistance to nematode parasite infections in small ruminants in tropical production systems," Animal, vol. 6, no. 5, pp. 741-747, 2012.

[78] A. M. Wren, C. J. Small, H. L. Ward et al., "The novel hypothalamic peptide ghrelin stimulates food intake and growth hormone secretion," Endocrinology, vol. 141, no. 11, pp. 4325-4328, 2000.

[79] A. Ingham, M. Menzies, P. Hunt, A. Reverter, R. Windon, and N. Andronicos, "Divergent ghrelin expression patterns in sheep genetically resistant or susceptible to gastrointestinal nematodes," Veterinary Parasitology, vol. 181, no. 2-4, pp. 194202, 2011.

[80] A. Dembinski, Z. Warzecha, P. Ceranowicz et al., "Ghrelin attenuates the development of acute pancreatitis in rats," Journal of Physiology and Pharmacology, vol. 54, no. 4, pp. 561-573, 2003.

[81] Z. Warzecha and A. Dembiński, "Protective and therapeutic effects of ghrelin in the gut," Current Medicinal Chemistry, vol. 19, no. 1, pp. 118-125, 2012.

[82] K. I. Altaif and J. D. Dargie, "Genetic resistance to helminths. The influence of breed and haemoglobin type on the response of sheep to re-infection with Haemonchus contortus.," Parasitology, vol. 77, no. 2, pp. 177-187, 1978.

[83] E. W. Allonby and G. M. Urquhart, "A possible relationship between haemonchosis and haemoglobin polymorphism in Merino sheep in Kenya," Research in Veterinary Science, vol. 20, no. 2, pp. 212-214, 1976.

[84] J. M. Preston and E. W. Allonby, “The influence of haemoglobin phenotype on the susceptibility of sheep to Haemonchus contortus infection in Kenya.," Research in Veterinary Science, vol. 26, no. 2, pp. 140-144, 1979.

[85] R. G. Windon, J. K. Dineen, and J. D. Kelly, “The segregation of lambs into "responders" and "non-responders": response to vaccination with irradiated Trichostrongylus colubriformis larvae before weaning," International Journal for Parasitology, vol. 10, no. 1, pp. 65-73, 1980.

[86] D. Wakelin and A. M. Donachie, "Genetic control of immunity to Trichinella spiralis: influence of $\mathrm{H}$-2-linked genes on immunity to the intestinal phase of infection," Immunology, vol. 48, no. 2, pp. 343-350, 1983.

[87] P. M. Outteridge, L. Andersson, P. G. C. Douch et al., "The PCR typing of MHC-DRB genes in the sheep using primers for an intronic microsatellite: application to nematode parasite resistance," Immunology and Cell Biology, vol. 74, no. 4, pp. 330336, 1996.

[88] T. J. Gill III, D. V. Cramer, and H. W. Kunz, "The major histocompatibility complex: comparison in the mouse, man, and the rat: a review," The American Journal of Pathology, vol. 90, no. 3, pp. 737-778, 1978.

[89] F. W. Schwaiger, D. Gostomski, M. J. Stear et al., "An ovine major histocompatibility complex DRB1 allele is associated with low faecal egg counts following natural, predominantly Ostertagia circumcincta infection," International Journal for Parasitology, vol. 25, no. 7, pp. 815-822, 1995.

[90] M. J. Stear, K. Bairden, S. C. Bishop et al., "An ovine lymphocyte antigen is associated with reduced faecal egg counts in fourmonth-old lambs following natural, predominantly Ostertagia circumcincta infection," International Journal for Parasitology, vol. 26, no. 4, pp. 423-428, 1996.

[91] C. Diez-Tascón, O. M. Keane, T. Wilson et al., "Microarray analysis of selection lines from outbred populations to identify genes involved with nematode parasite resistance in sheep," Physiological Genomics, vol. 21, pp. 59-69, 2005.

[92] O. M. Keane, K. G. Dodds, A. M. Crawford, and J. C. McEwan, "Transcriptional profiling of Ovis aries identifies Ovar-DQA1 allele frequency differences between nematode-resistant and susceptible selection lines," Physiological Genomics, vol. 30, no. 3, pp. 253-261, 2007.

[93] J. A. F. Castillo, R. D. M. Medina, J. M. B. Villalobos et al., "Association between major histocompatibility complex microsatellites, fecal egg count, blood packed cell volume and blood eosinophilia in Pelibuey sheep infected with Haemonchus contortus," Veterinary Parasitology, vol.177, no. 3-4, pp. 339-344, 2011.

[94] E. A. Brown, J. G. Pilkington, D. H. Nussey et al., "Detecting genes for variation in parasite burden and immunological traits in a wild population: testing the candidate gene approach," Molecular Ecology, vol. 22, no. 3, pp. 757-773, 2013.

[95] B. L. Sayre and G. C. Harris, "Systems genetics approach reveals candidate genes for parasite resistance from quantitative trait loci studies in agricultural species," Animal Genetics, vol. 43, no. 2, pp. 190-198, 2012.

[96] D. W. Coltman, K. Wilson, J. G. Pilkington, M. J. Stear, and J. M. Pemberton, "A microsatellite polymorphism in the $\gamma$ interferon gene is associated with resistance to gastrointestinal nematodes in a naturally-parasitized population of Soay sheep," Parasitology, vol. 122, no. 5, pp. 571-582, 2001.

[97] O. M. Keane, A. Zadissa, T. Wilson et al., "Gene expression profiling of Naïve sheep genetically resistant and susceptible to gastrointestinal nematodes," BMC Genomics, vol. 7, article 42, 2006.

[98] N. Andronicos, P. Hunt, and R. Windon, "Expression of genes in gastrointestinal and lymphatic tissues during parasite infection in sheep genetically resistant or susceptible to Trichostrongylus colubriformis and Haemonchus contortus," International Journal for Parasitology, vol. 40, no. 4, pp. 417-429, 2010.

[99] J. G. H. Hickford, R. H. J. Forrest, H. Zhou, Q. Fang, and C. M. Frampton, "Association between variation in faecal egg count for a mixed field-challenge of nematode parasites and ovine MHC-DQA2 polymorphism," Veterinary Immunology and Immunopathology, vol. 144, no. 3-4, pp. 312-320, 2011.

[100] K. E. Kemper, D. L. Emery, S. C. Bishop et al., "The distribution of SNP marker effects for faecal worm egg count in sheep, and the feasibility of using these markers to predict genetic merit for resistance to worm infections," Genetics Research, vol. 93, no. 3, pp. 203-219, 2011.

[101] A. A. Swan, D. J. Johnston, D. J. Brown, B. Tier, and H. Graser, "Integration of genomic information into beef cattle and sheep genetic evaluations in Australia," Animal Production Science, vol. 52, no. 2-3, pp. 126-132, 2012.

[102] G. Biozzi, D. Mouton, Y. Bouthillier, and J. C. Mevel, "Amplification of the 'High' and 'Low' antibody production characteristics resulting from bidirectional selective breeding in the mouse. Correlation between immunodeficiency and lymphoma incidence," in Amplification des Caracteres 'Bonne Production' ou 'Mauvaise Production' D'anticorps, Produits par Selection Genetique Chez la Souris. Correlation Entre L'immunodeficience et L'incidence de Lymphomes, vol. 299, pp. 753-758, 1984. 
[103] Y. Gao, L. Flori, J. Lecardonnel et al., "Transcriptome analysis of porcine PBMCs after in vitro stimulation by LPS or PMA/ionomycin using an expression array targeting the pig immune response," BMC Genomics, vol. 11, no. 1, article 292, 2010.

[104] L. Flori, Y. Gao, D. Laloë et al., "Immunity traits in pigs: substantial genetic variation and limited covariation," PLOS ONE, vol. 6, no. 7, Article ID e22717, 2011.

[105] K. A. Thompson-Crispi, B. Hine, M. Quinton, F. Miglior, and B. A. Mallard, "Short communication: association of disease incidence and adaptive immune response in Holstein dairy cows," Journal of Dairy Science, vol. 95, no. 7, pp. 3888-3893, 2012.

[106] K. A. Thompson-Crispi, F. Miglior, and B. A. Mallard, "Incidence rates of clinical mastitis among Canadian holsteins classified as high, average, or low immune responders," Clinical and Vaccine Immunology, vol. 20, no. 1, pp. 106-112, 2013.

[107] G. Banos, E. Wall, M. P. Coffey et al., "Identification of immune traits correlated with dairy cow health, reproduction and productivity," PLoS ONE, vol. 8, no. 6, Article ID e65766, 2013.

[108] A. J. Wilsmore, M. Dawson, M. J. Arthur, and D. C. Davies, "The use of a delayed hypersensitivity test and long-acting oxytetracycline in a flock affected with ovine enzootic abortion," The British Veterinary Journal, vol. 142, no. 6, pp. 557-561, 1986.

[109] T. L. W. Rothwell, R. G. Windon, B. A. Horsburgh, and H. I. Davies, "Some cutaneous responses to mitogen injection in sheep, with special reference to eosinophil leucocytes," Research in Veterinary Science, vol. 51, no. 1, pp. 44-47, 1991.

[110] H. S. Gill, "Cell-mediated immunity in merino lambs with genetic resistance to Haemonchus contortus," International Journal for Parasitology, vol. 24, no. 5, pp. 749-756, 1994. 


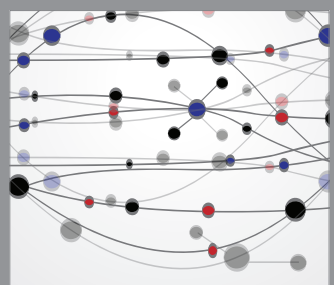

The Scientific World Journal
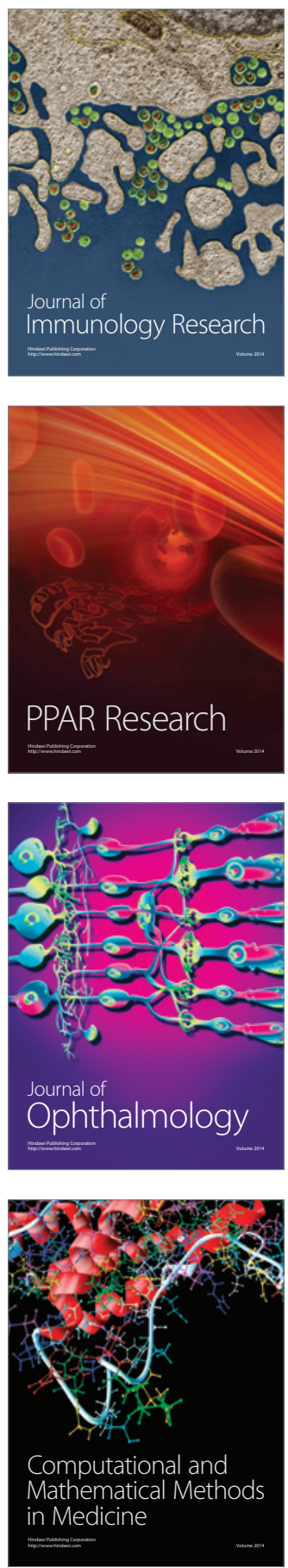

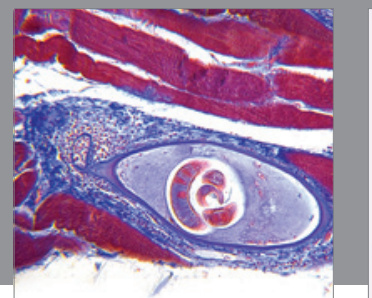

Gastroenterology

Research and Practice
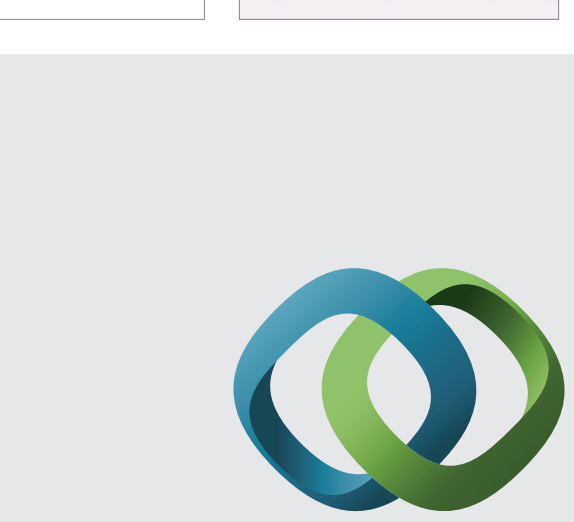

\section{Hindawi}

Submit your manuscripts at

http://www.hindawi.com
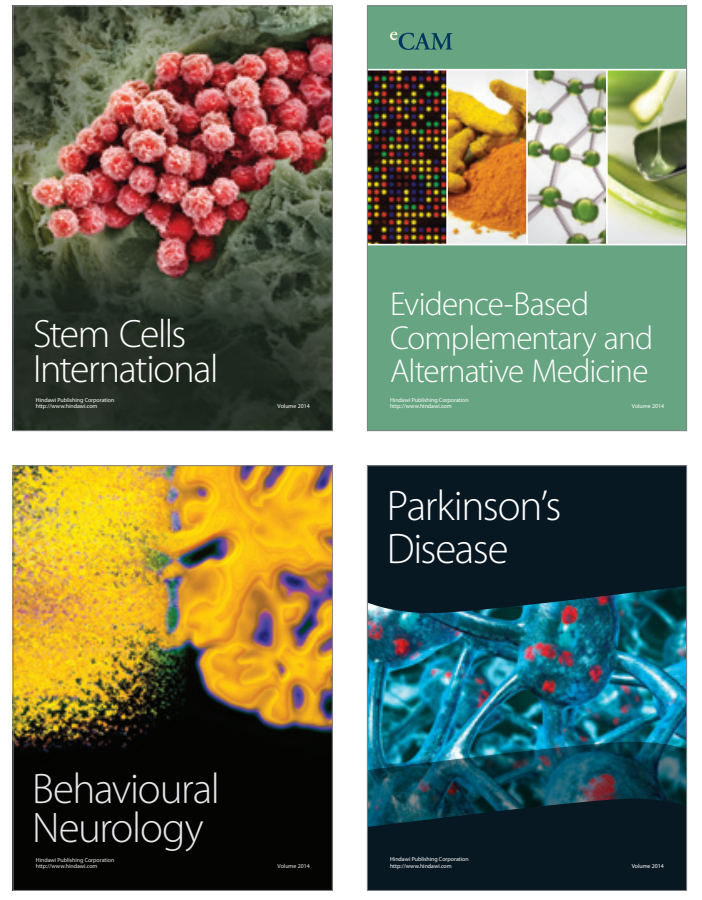
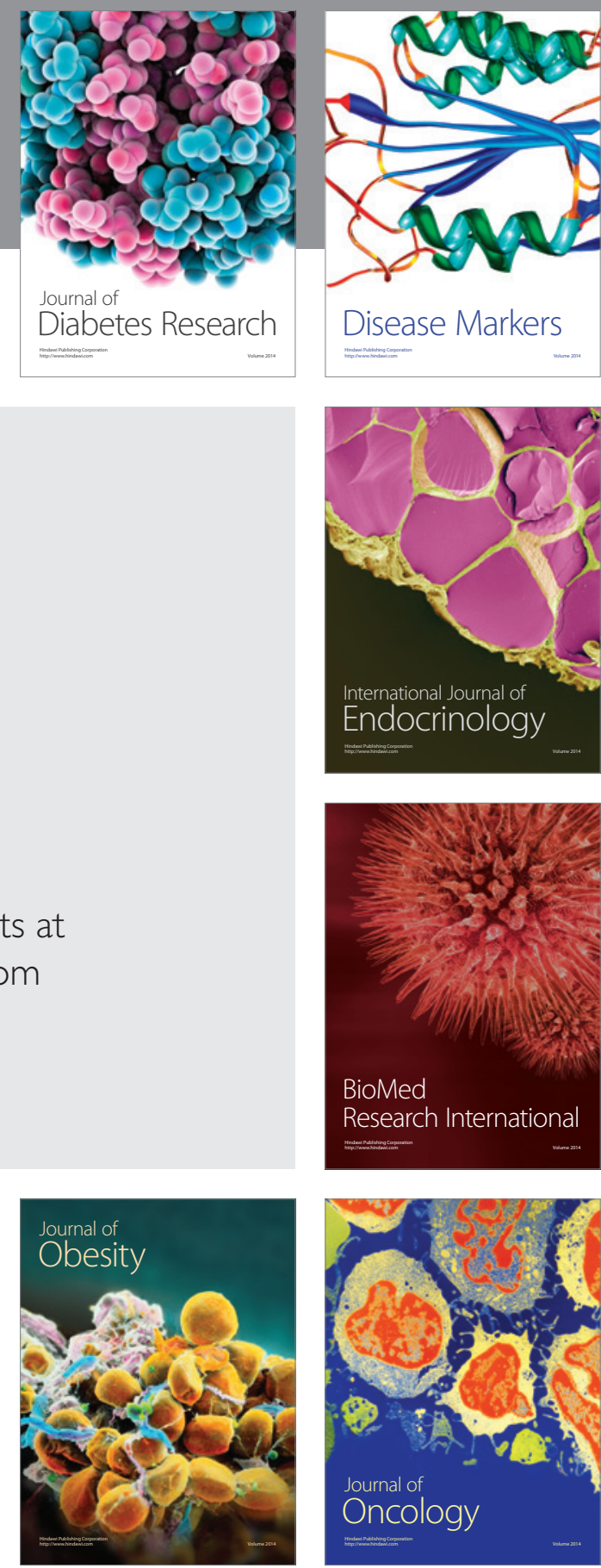

Disease Markers
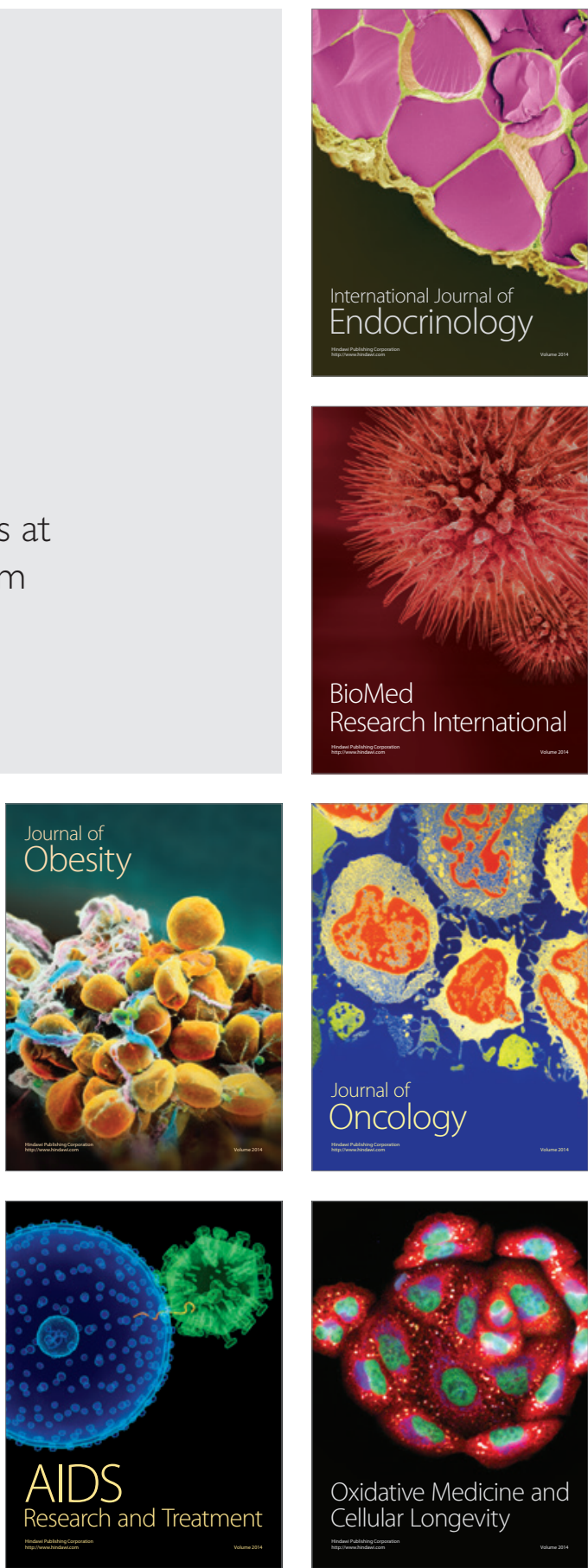